\title{
LAS PUNTAS DE ESCOTADURA SOLUTRENSES DE CHAVES Y DE FUENTE DEL TRUCHO (HUESCA, ESPAÑA)
}

\section{The solutrean notched points from Chaves and Fuente del Trucho (Huesca, Spain)}

\author{
Rafael Domingo ${ }^{1,2}$, Lourdes Montes ${ }^{1,2}$ y Pilar Utrilla ${ }^{1,3}$
}

Recibido el 27 de febrero de 2013. Aceptado el 22 de mayo de 2013

Resumen. Se presentan los resultados del análisis funcional aplicado a una breve colección de puntas de escotadura de los niveles solutrenses de Chaves y Fuente del Trucho, en el Prepirineo oscense (España). Se documentan además las fuertes similitudes que las ocupaciones de estas cuevas presentan con el Salpetriense del sureste francés, frente a las peculiaridades regionales que se pueden identificar en la costa levantina peninsular.

Palabras clave: Solutrense, Salpetriense, valle del Ebro, norte de España, industria lítica, análisis funcional.

Abstract. We present the results from the functional analysis applied to a short collection of notched points from the Solutrean levels found in Chaves and Fuente del Trucho, both in the Prepyrenees in Huesca province (Spain). We also document the strong similarities between these caves and the Salpetrian from SE France, versus the regional peculiarities that have been identified in the Peninsular Levantine coast.

Keywords: Solutrean, Salpetrian, Ebro Basin, North of Spain, lithic industry, functional analysis.

\section{INTRODUCCIÓN}

El valle del Ebro se está revelando en los últimos años como uno de los territorios más importantes para el estudio del poblamiento prehistórico de la Península Ibérica (Utrilla et al. 2010). Su privilegiada posición a caballo entre las costas cantábrica y mediterránea, el sur de Francia y la meseta española, y sus múltiples ambientes climáticos y paisajísticos le otorgan un indudable papel protagonista en la investigación prehistórica. Especialmente ricos resultan los territorios de piedemonte ("somontanos") y las zonas más húmedas y de clima menos extremo de la zona noroccidental, mientras que amplias extensiones del tramo medio de la cuenca presentan notables vacios, especialmente en cuanto a las ocupaciones paleolíticas. Esto es debido tanto a la ausencia de refugios naturales como a la profunda erosión que desde el
Holoceno ha modificado notablemente el entorno, arrasando zonas en relieve y cubriendo las partes bajas. Probablemente las gentes paleolíticas ocuparon también las zonas llanas, ricas en sílex de gran calidad, pero sus asentamientos son muy dificiles de localizar, enterrados por aluviones holocenos y/o afectados por intensas labores agrícolas.

El comienzo del Paleolítico superior está relativamente bien representado con, por el momento, siete enclaves datados que se adscriben al Auriñaciense y al Gravetiense; se sitúan en territorios distantes entre sí pero con caracteristicas similares: en las estribaciones de relieves de cierta importancia y junto a cursos de agua. Entre ellos, se documentan presencias auriñacienses en la cueva de Peña Miel (sierra de Cameros, La Rioja) o el abrigo de Los Toros de Cantavieja (sur del Maestrazgo turolense), y gravetienses en el abrigo de Ángel 1 del Arenal de Fonseca (norte del Maestrazgo tu-

(1) Grupo "Primeros pobladores del Valle del Ebro" de la Universidad de Zaragoza.

(2) Área de Prehistoria. Universidad de Zaragoza.Plaza Constitución, s/n. E-22001 Huesca.rdomingo@unizar.es·Imontes@unizar.es

(3) Área de Prehistoria. Universidad de Zaragoza. Calle Pedro Cerbuna, 12. E-50009 Zaragoza. utrilla@unizar.es 
rolense). Estas presencias humanas muestran rasgos bien definidos, que se asocian con las zonas vecinas, mejor conocidas: la costa cantábrica en el caso de los enclaves del Ebro noroccidental y la mediterránea en el caso de la suroriental (Domingo et al. 2013).

El Solutrense del valle del Ebro resulta por el momento algo más esquivo (aparece tratado específicamente en Utrilla y Mazo 1994 y dentro de un encuadre mayor en Utrilla y Montes 2007, además de en el ya citado Utrilla et al. 2010). Se ha documentado materialmente en un número escaso de enclaves, todos de la margen izquierda del Ebro, y principalmente en su parte noroccidental, donde sin embargo no se han podido obtener fechas radiocarbónicas. En muchos lugares su presencia es anecdótica o simplemente se sospecha de su existencia a través del hallazgo de piezas concretas (casos de Leginpea o Portugain) para las que se carece de un contexto claro. La única ocupación bien datada hasta el momento es el nivel $\mathrm{c} 1$ de la cueva de Chaves, en las estribaciones meridionales de la sierra de Guara; cercano a ella, el gran abrigo de la Fuente del Trucho presenta un relleno pulverulento, revuelto por el uso del sitio como corral en épocas recientes, con numerosas piezas de tipología superopaleolítica entre las que se encuentran algunas de indudable aspecto solutrense (incluyendo varias de retoque plano y dos puntas escotadas de retoque abrupto).

Es precisamente este último tipo de herramienta el que actúa como hilo conductor para la redacción de este trabajo: las puntas de retoque abrupto con muesca o escotadura (de las dos maneras son mencionadas en la bibliografía en español, traduciendo el término francés pointes à cran) son características de las ocupaciones solutrenses de la costa mediterránea (Fig. 1), desde el valle del Ródano al estrecho

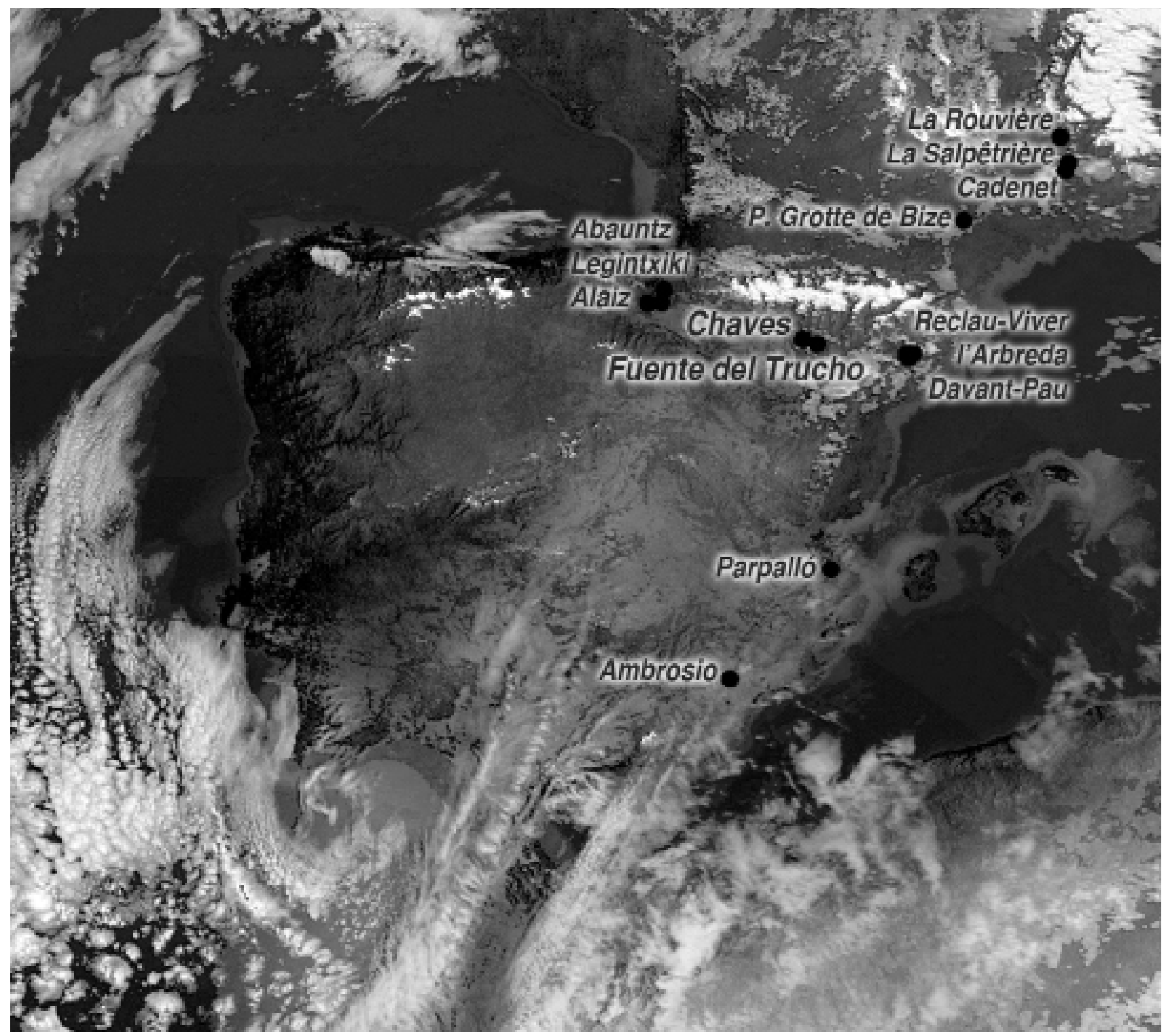

A FiguRA 1. Localización de los principales yacimientos citados sobre una recreación de la Península Ibérica y el sur de Francia durante el Pleniglacial (base: Ittiz). 
de Gibraltar, siendo muy escasas o estando totalmente ausentes en territorios del interior o de la costa cantábrica (pudiendo citar cuatro ejemplares procedentes de los yacimientos navarros de Alaiz, Legintxiki y Abauntz). El conjunto más numeroso en el valle del Ebro procede, por tanto, de la cueva de Chaves, donde se registran 16 ejemplares. En este artículo se estudian desde el punto de vista morfotécnico (contrastándolos con los ejemplares localizados en otros enclaves de la costa mediterránea) y funcional (presentando los resultados de su análisis traceológico).

\section{CHAVES Y FUENTE DEL TRUCHO, LUGARES ESPECIALES EN EL PREPIRINEO CENTRAL}

Los enclaves de Chaves y Fuente del Trucho (Fig. 2) son sobradamente conocidos en la literatura prehistórica desde comienzos de los años 80 del siglo XX, si bien han sido tradicionalmente más valorados por otros niveles arqueológicos (Magdaleniense superior y Neolítico antiguo en el caso de Chaves, Musteriense en el de Fuente del Trucho) que por sus ocupaciones solutrenses, comparativamente de escasa entidad.

La cueva de Chaves (Bastarás, Casbas de Huesca) es una enorme cavidad que forma parte de una amplia red kárstica al pie de la sierra de Guara, en la red fluvial del río Formiga, uno de los afluentes del Alcanadre, que a su vez forma parte de la gran cuenca del Cinca. Se abre a unos $650 \mathrm{~m}$ de altitud, orientada a sol naciente, con un gran porche de unos $60 \mathrm{~m}$ de anchura por $30 \mathrm{~m}$ de alto. La parte practicable de la cueva se extiende unos $200 \mathrm{~m}$ hacia el interior, y la zona efectivamente habitable ocupa una superficie de alrededor de $3.000 \mathrm{~m}^{2}$ a resguardo. Las condiciones para la ocupación humana son así inmejorables, lo que se plasma en los nive- les arqueológicos que acoge: los más importantes son los dos datados en el Neolítico antiguo, con unos 70.000 restos localizados a lo largo de casi tres decenios de trabajos. Se trataria de un gran asentamiento que testimonia una de las presencias neolíticas más antiguas de la Península Ibérica, con fechas radiocarbónicas de vida corta que se remontan hasta la primera mitad del VII milenio cal a. C. La cueva acoge también un campamento del Magdaleniense superior, el más notable de la zona central de la cuenca, excavado entre 1984 y 1998 por P. Utrilla (Utrilla, 1992 y 2000). Por lo que se refiere al solutrense, se trata de una pequeña ocupación que entregó apenas unos cientos de restos, al abrigo de grandes bloques caídos del techo que la protegieron de la acción erosiva de los procesos fluviokársticos que barrieron amplias zonas del vestíbulo. Esta ocupación, repartida en dos pequeños lentejones cenicientos localizados entre niveles estériles de arroyada (c1 y c2), fue datada, mediante radiocarbono convencional con una muestra única de carbón procedente del nivel c1, en $19700 \pm 310$ BP (GrN-12681; $23650 \pm 650$ cal BP, HULU 2007). Las actividades arqueológicas en la cueva se vieron bruscamente interrumpidas en 2008 tras el vaciado de buena parte del sedimento aun no excavado por parte de los propietarios del coto de caza en el cual se encuentra el yacimiento.

A $30 \mathrm{~km}$ al este se abre el gran abrigo de la Fuente del Trucho, en la parte final del barranco de Villacantal, uno de los tributarios del río Vero, en pleno corazón de los cañones de Guara. Se trata de un covacho abierto a sol naciente, perfectamente situado en una de las zonas de acceso al encajado curso del río, que acoge las que hasta el momento son las únicas pinturas rupestres paleolíticas del territorio aragonés. El relleno arqueológico fue parcialmente excavado por A. Mir en los años 80 (Mir y Salas 2000), quien localizó restos de filiación musteriense, y por Utrilla y Montes en

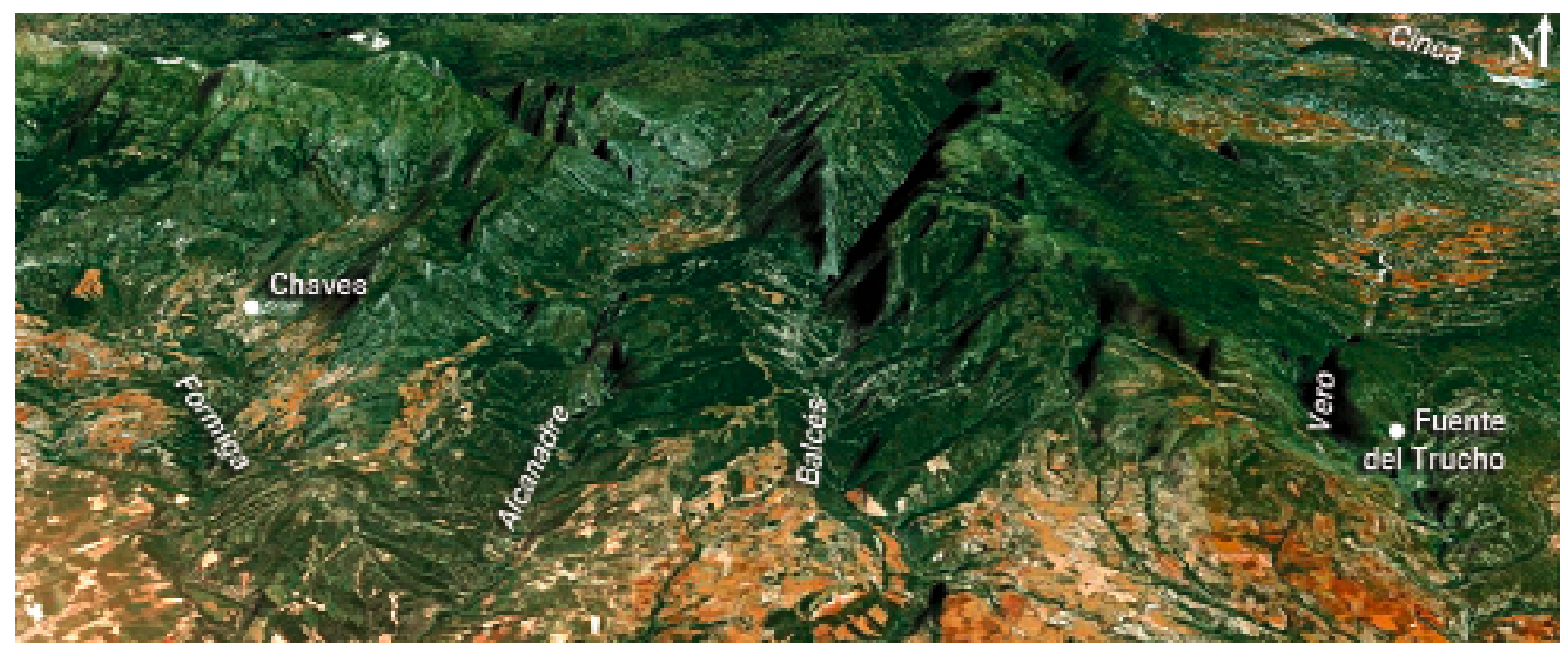

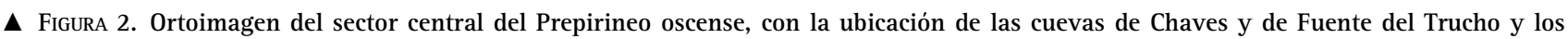
principales cursos fluviales (base: Google Earth). 
2005 (Montes et al. 2006), que sondearon la zona al pie de los grabados exteriores y la situada en la pared opuesta, enmarcando así la cata de Mir. Al pie de los grabados el material localizado fue altomedieval, aunque se tocaron niveles musterienses en la zona más cercana al centro de la cavidad. En el otro extremo del abrigo el sedimento, de matriz muy fina, casi pulverulenta, se hallaba completamente revuelto por su uso como corral (aún se conserva el muro de cierre, en piedra seca), ofreciendo un material arqueológico claramente superopaleolítico: desde elementos de aire auriñaciense hasta piezas características de los periodos gravetiense y solutrense (las puntas de escotadura que tratamos en este trabajo y otros objetos de retoque plano). Todo ello testimonia una ocupación intensa del enclave desde el $\mathrm{Pa}$ leolítico medio y a lo largo de todo el Paleolítico superior, a base de visitas reiteradas de grupos humanos, algunos de los cuales dejaron pinturas que podemos asociar claramente con santuarios situados en otras regiones. Existen indudables similitudes con la cueva francesa de Gargas, apenas unos $100 \mathrm{~km}$ al norte, atravesando la cordillera pirenaica: en ambos encontramos representaciones, adscritas al periodo gravetiense, de manos en negativo con ausencia de falanges, circunstancia excepcional en el arte prehistórico, pues resulta testimonial o está totalmente ausente en el resto de cuevas (Utrilla et al. 2013).

\section{EL SALPETRIENSE FRANCÉS Y SUS PARALELOS PENINSULARES}

Los estudios de G. Boccaccio (Boccaccio 2005 y Boccaccio y Utrilla 2013) han confirmado que el Solutrense del valle medio del Ebro presenta claras similitudes materiales con el Salpetriense del sureste francés. Dado a conocer por Escalon de Fonton (1964), el yacimiento epónimo es la cueva de La Salpêtrière, junto al río Gard, afluente del Ródano, y ha sido localizado con claridad en otros dos enclaves, el campamento al aire libre de La Rouvière en Ardèche y el yacimiento de Cadenet, también en el Gard. El sitio de La Salpêtrière es el único que ha ofrecido una serie de dataciones radiocarbónicas, un total de cinco fechas convencionales que se extienden entre el 18500 y el 19500 BP. Lo más significativo de la industria lítica es la relativa abundancia de puntas de escotadura de retoque abrupto, denominadas de tipo mediterráneo. Estas piezas suponen más del 10\% de los elementos retocados en los tres sitios. Según Boccaccio esos yacimientos se caracterizan por una evidente similitud tecnológica, que permite confirmar la homogeneidad cultural del Salpetriense antiguo. Esas características lo singularizan con claridad respecto al Solutrense superior y a otras culturas cronológicamente similares en Francia y España, excepción hecha del nivel c1 de Chaves. La industria material localizada en la cueva oscense resulta claramente distinta de la recuperada en otros conjuntos de finales del Solutrense español, sobre todo por las particularidades de sus puntas de escotadura, a lo que se añade una datación relativamente antigua en comparación con lo que se conoce para otros sitios de la costa mediterránea. De norte a sur, los más destacados de esos yacimientos son los tres enclaves de Serinyà (Reclau Viver, I'Arbreda y Davant-Pau), donde las puntas son cortas y anchas; Parpalló, con una serie de piezas muy numerosa; y Ambrosio, en el que destaca la escasa estandarización de los soportes elegidos para la confección de estas puntas. En estos dos últimos sitios es frecuente, al contrario que en el Salpetriense francés y en Chaves, la reducción de la anchura de las puntas mediante retoque abrupto en el lateral opuesto a la escotadura.

\subsection{Las puntas de escotadura en el valle del Ebro: entre Languedoc y el Levante}

Los análisis de Boccaccio concluyen que la colección de puntas de escotadura de Chaves presentan características morfotécnicas que las asimilan con mayor claridad a los conjuntos del Salpetriense francés que a los del Levante peninsular (Fig. 3). En sus magnitudes máximas, las piezas de Chaves se acercan más a las puntas largas y estilizadas del sureste francés que a las diminutas de Ambrosio y Parpalló o a las cortas y anchas del Serinyà. En consonancia, la longitud de la escotadura es también mayor en las piezas de Chaves (14 $\mathrm{mm}$ ) que en las del Levante (8 a $12 \mathrm{~mm}$ ), aproximándose a las de los conjuntos salpetrienses del Ródano (16 a $17 \mathrm{~mm}$ ). El pedúnculo es en Chaves, como en el núcleo francés, rectilíneo, mientras que en las piezas del sureste peninsular presentan ocasionalmente morfologías "en forma de coma". Otro elemento significativo es la frecuente presencia de un dorso opuesto a la escotadura en las piezas del Levante español, desconocido tanto en Chaves como en el conjunto del sureste francés.

Las similitudes entre el conjunto del Prepirineo central y el grupo del Ródano testimonian la que por ahora parece ser la utilización más antigua de una vía de comunicación (de ideas y/o personas) recurrente en las últimas fases de la Prehistoria: el corredor Aude-Têt-Segre-Cinca (Fig. 4). La vía de comunicación seguiría principalmente los cursos fluviales de los ríos Aude y Têt, para acceder desde el norte, y Segre, desde el sur, atravesando la cordillera pirenaica unos $80 \mathrm{~km}$ al oeste del corredor costero. La vía de la costa parecería la más obvia para un momento frío en el que el glaciarismo pirenaico, si bien ya estaba lejos de sus máximos, documentados grosso modo entre 75 y $50 \mathrm{ka}$, se encontraba en un momento de reavance de cierta importancia, datado entre 25 y $18 \mathrm{ka}$. En otros puntos más occidentales del Pirineo, mejor estudiados, se documentan para esta época lenguas glaciares de $14 \mathrm{~km}$ de longitud y $200 \mathrm{~m}$ de espesor, con morrenas terminales a unos $1100 \mathrm{~m}$ de altitud 


\section{Longitud de la escotadura (media en mm)}

Ambrosio

Parpallo 3,75-4

Parpallo 4-4,75

Parpalló 4,75-5,25

Chaves

Salpêtrière

Rouviere

Oulins
8,5

7
8,2
12
14,3
15,6
15,7
16,8

\section{Forma del pedúnculo}

Chaves y Salpetriense

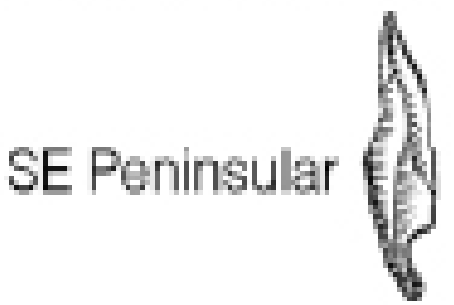

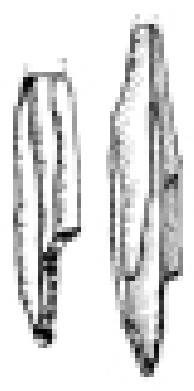

\section{LM/escotadura}

Parpalló Solut. sup 2,85 Ambrosio 2,88

Chaves

Salpêtrière 3,84

\section{Estilización}

Chaves y Salpetriense

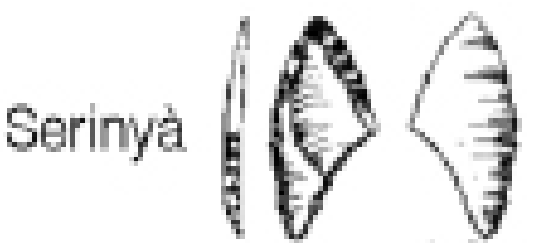

A Figura 3. Esquema de los principales caracteres morfológicos de las puntas escotadas de retoque abrupto, tipo Salpêtrière.

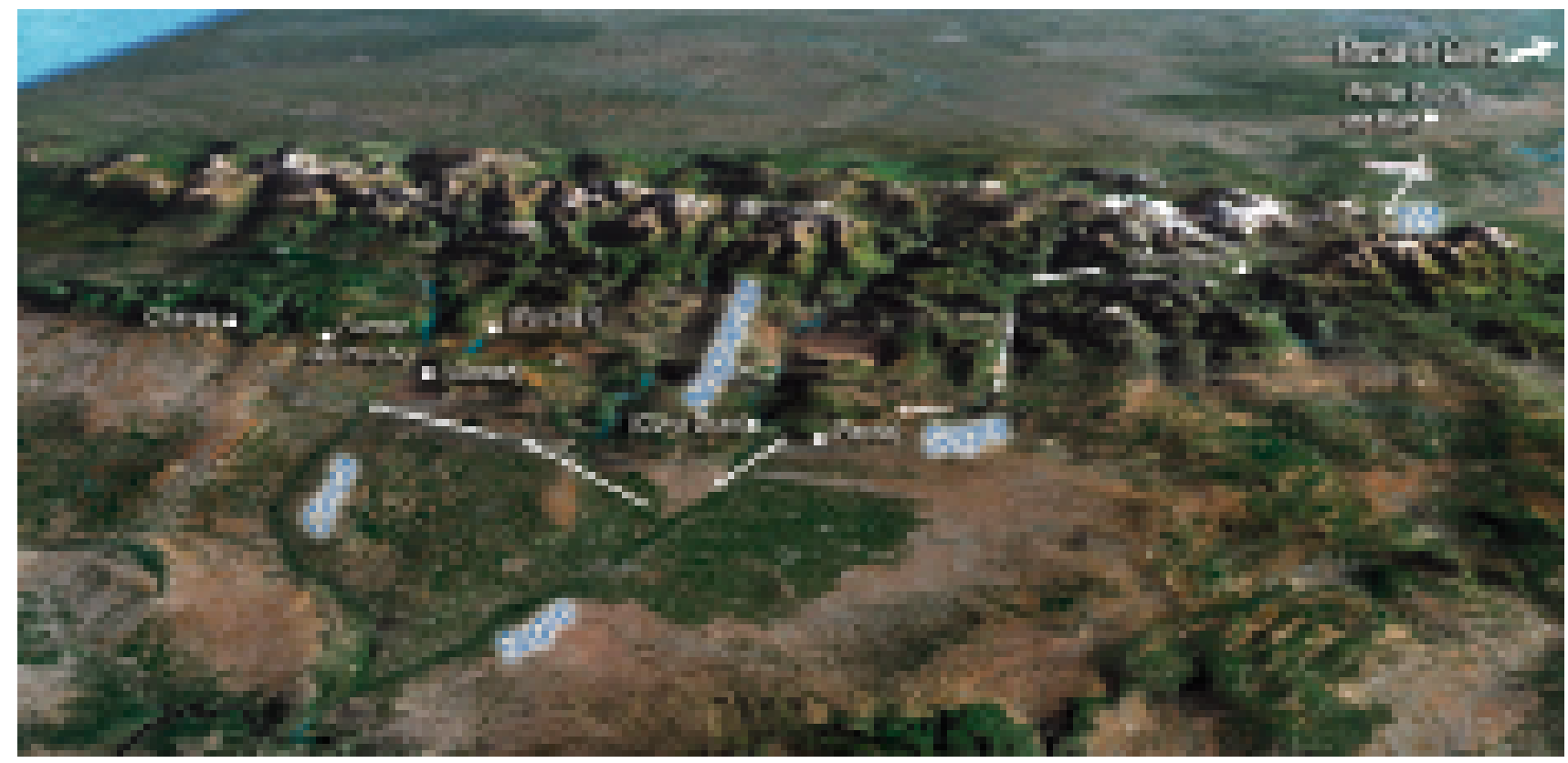

A Figura 4. Posible ruta de comunicación entre el sureste francés y el Prepirineo central. Entre paréntesis, yacimientos magdalenienses con fechas antiguas documentados en la ruta (base: Google Earth). 


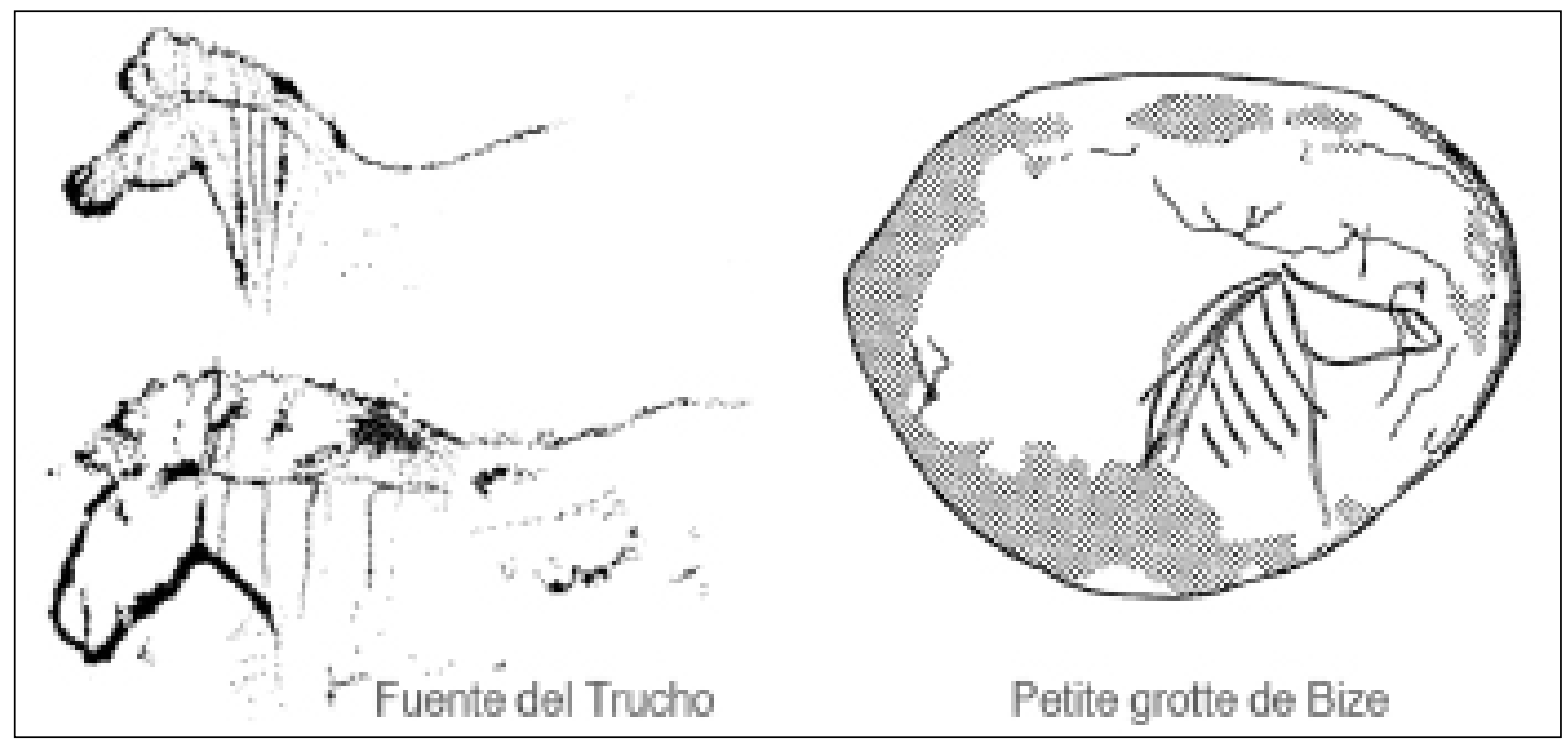

$\Delta$ Figura 5. Comparación de las representaciones de caballos de Fuente del Trucho y la Petite grotte de Bize (según Utrilla et al., 2013 y Sacchi, 1986).

(García-Ruiz y Martí-Bono, 2011). Pero según Calvet (2004), la depresión intramontana de la Cerdaña y que comunica las cabeceras de los ríos Aude, Têt y Segre nunca llegó a estar ocupada por glaciares de forma total, lo que permitiria una comunicación franca entre los territorios situados en las zonas centrales de ambas vertientes, sin necesidad de rodear la cordillera pirenaica por sus extremos cantábrico o mediterráneo.

En este sentido, el yacimiento de la Petite Grotte de Bize, sobre el río Cesse, afluente del Aude, ha aportado elementos de arte mueble que lo vinculan indudablemente con la Fuente del Trucho. Como se observa en la figura 5, los prótomos de caballo de ambas cavidades presentan similitudes notables: esquematismo en la representación de los detalles, despiece en el cuello a base de líneas paralelas, quijada muy marcada, orejas apenas insinuadas y crinera destacada, lo que es más notable en el caso altoaragonés. El conjunto material fue excavado en los años 30 del siglo XX y ha sido posteriormente reestudiado por Sacchi (1986) y Boccaccio (2005). El primero estableció claramente la existencia de ocupaciones solutrenses genéricas, mientras que el segundo intuyó la presencia del Salpetriense a partir de diversos rasgos técnicos de la gestión de la talla y de la existencia de una serie de puntas de escotadura de retoque abrupto que en líneas generales resultan muy similares a las del núcleo del Ródano. Boccaccio advierte, sin embargo, que algunas de las puntas de Bize muestran rasgos compartidos por las piezas de Serinyà (soportes cortos y anchos) y por las del levante meridional peninsular (pedúnculos "en coma"), inéditos en el sureste francés, lo que implica que en este yacimiento se observaría una concentración de elementos técnicos característicos tanto del núcleo original Salpe- triense como de los enclaves ibéricos. No se han localizado hasta el momento yacimientos solutrenses que jalonen la ruta propuesta entre Bize y Chaves/Trucho, pero sí inmediatamente posteriores, como el sitio al aire libre de Montlleó, datado en 15500 BP. Situado en la cuenca alta del Segre, a casi $1.200 \mathrm{~m}$ de altitud, se localiza en plena depresión de la Cerdaña y a escasa distancia de las cabeceras de los valles del Aude y el Têt. Siguiendo el río Segre hacia el sur se documentan ocupaciones del Magdaleniense inferior en Parco, Cova Gran, Forcas-I y Alonsé, todas ellas con fechas entre el 15000 y el 14000 BP. Es posiblemente cuestión de tiempo (y de trabajo de campo...) el hallazgo de asentamientos solutrenses a lo largo de esta importante vía de comunicación natural (Mangado et al. 2010; Utrilla et al. 2010; Montes y Domingo, 2013).

Fuente del Trucho presenta, pese a los problemas ya citados por el carácter revuelto del sedimento, algunas caracteristicas que resultan sumamente sugestivas: según $A$. Tarriño (com. pers.) las piezas solutrenses de retoque plano están realizadas sobre un sílex de tipo evaporítico que sería más característico de la margen derecha del río Ebro, mientras que alguna de las puntas de escotadura de retoque abrupto está fabricada con un sílex "de aire francés". ¿Testimonia esto la presencia de dos grupos distintos, uno representado por las piezas de origen y estilo norpirenaico, y otro por las herramientas de origen meridional? Las figuras rupestres, con dos "estilos" de representar los caballos, uno más realista, con cuellos listados (como en el bloque de Bize), y otro más esquemático, con figuras de cuello largo, apoyarian esta hipótesis. Desgraciadamente, la heterogeneidad del registro arqueológico conservado impide ofrecer una respuesta concluyente a estas consideraciones. 


\subsection{Análisis funcional de las puntas de escotadura del valle del Ebro}

Para complementar el estudio se realizó un análisis funcional de las puntas de escotadura de Chaves (Fig. 6) y Fuente del Trucho, así como de los ejemplares de Alaiz y Legintxiki. Utilizamos para ello un microscopio metalográfico con un rango de aumentos entre 40x y 400x, aunque las observaciones principales se realizaron a 100 aumentos, tomando imágenes digitales de 5 megapíxeles de resolución. Los resultados fueron poco significativos debido, por un lado, a lo reducido de la muestra, y por otro a los problemas derivados de su observación a altos aumentos, afectada notablemente por la proliferación de pátinas y lustres, especialmente en los ejemplares de la cueva de Chaves. Esos mismos problemas ya habian sido identificados en observaciones anteriores realizadas en otros materiales de la misma cueva (Domingo e. p. b) y se deben probablemente a la circulación fluviokárstica superficial, frecuente en el sistema de cuevas de Chaves-Solencio, donde hasta la acualidad se registran surgencias repentinas en los momentos de máximo nivel del freático, alimentado por escorrentía y filtraciones de una amplia zona al pie de las cumbres de Guara.

A efectos comparativos, contábamos con una experimentación previa de envergadura (Domingo 2005), que consistió en el uso de unos 140 microlitos geométricos como puntas y filos laterales de flecha, a lo que se añade el estudio de casi dos millares de piezas arqueológicas: aproximadamente 800 geométricos del Mesolítico y Neolítico del valle del Ebro (Domingo 2009) y más de un millar de puntas de dorso magdalenienses de la grotte Gazel en las estribaciones de la Montagne Noire, en el sur de Francia (Domingo, en Sacchi e. p. a) Aunque las morfologías son claramente distintas, las huellas funcionales derivadas del uso como proyectil son asimilables, tanto a nivel microscópico (micropulidos lineales y estrías derivados del roce de pequeños fragmentos desprendidos del borde de las piezas en el momento del impacto) como macroscópico (roturas aburiladas y en charnela, tanto en el extremo distal como en el proximal, en este segundo caso debido al rebote contra el astil).
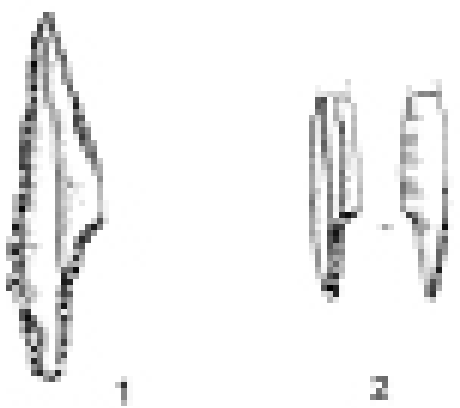

7

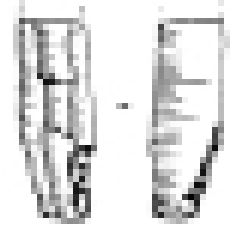

7

I
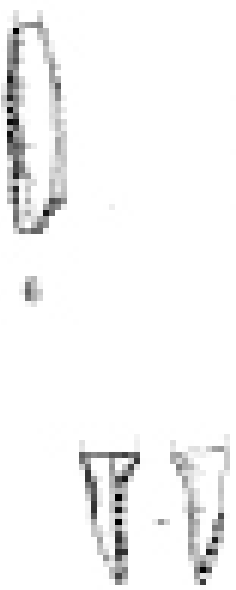

11

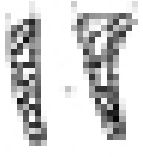

11

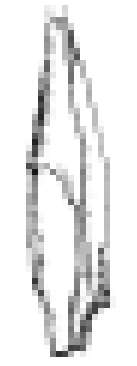

4

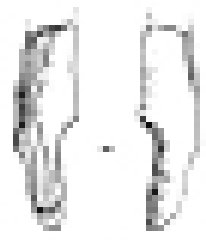

s

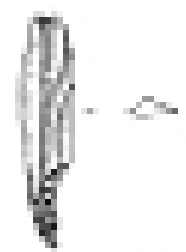

11

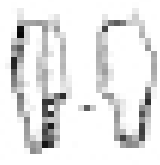

A

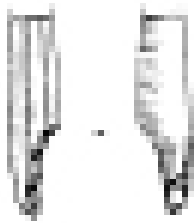

3

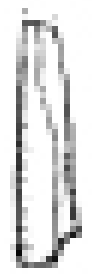

14

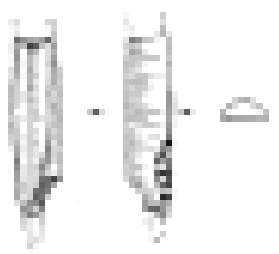

14

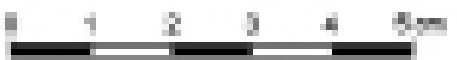

\ Figura 6. Puntas de escotadura del nivel solutrense de Chaves (dibujos: M. ${ }^{a}$ Cruz Sopena). 
La primera conclusión que debemos retener de las experimentaciones es la baja frecuencia de aparición de huellas funcionales sobre elementos de proyectil: entre el 30 y el $40 \%$ de las piezas disparadas una vez no muestran ninguna huella. Lógicamente, la probabilidad de aparición aumenta si se prolonga su uso, pero creemos que las puntas salpetrienses no soportarian muchos disparos reiterados, debido a su estilización, que las hace sumamente frágiles. En cualquier caso, y como sucede con la gran mayoría de los proyectiles líticos, su tiempo de fabricación es muy breve y su pérdida o rotura no supone un grave perjuicio para los cazadores prehistóricos, quienes sí dedicarían mayores esfuerzos a recuperar y reparar los astiles, que son las partes verdaderamente "costosas" de los proyectiles (Fischer et al. 1984).

Los conjuntos líticos formados por proyectiles obedecen a procesos de acumulación particulares, distintos a los de otros tipos de herramientas prehistóricas, ya que por su propio carácter la utilización tiene lugar fuera de los asentamientos. Para empezar, es posible encontrar stocks de piezas sin utilizar, fabricadas con la intención de servir de recambio en futuras operaciones de mantenimiento de los proyectiles pero que nunca llegaron a ser empleadas y, al abandonar las gentes prehistóricas el asentamiento, quedaron abandonadas. Las armaduras que sí han sido utilizadas (fuera del enclave, no lo olvidemos) pueden retornar al lugar de habitación de dos formas principales: bien insertadas en las presas cazadas, siendo localizadas y desechadas durante el procesado de la carne, o bien todavía montadas en los astiles. Si no han sufrido daños durante la caza, lo más probable es que al abandonar el lugar las gentes prehistóricas se lleven los proyectiles, dado la fuerte inversión en tiempo y trabajo que supone fabricar los astiles. Si las puntas se han roto por el uso, podemos esperar encontrar en el sitio los fragmentos proximales que, aún adheridos, fuesen desechados durante las tareas de reparación del armamento. Como vemos en la figura 6 , al menos de 10 de las piezas de la cueva de Chaves responden a este patrón, siendo fragmentos proximales o meso-proximales que probablemente serian usados en expediciones de caza durante las que sufrieron los desperfectos que podemos comprobar. De vuelta en el campamento, los cazadores solutrenses desmontarian las puntas rotas, las abandonarian alli y las reemplazarian por ejemplares nuevos. El principal problema para reconocer las piezas sin usar, discriminándolas de las que sí fueron

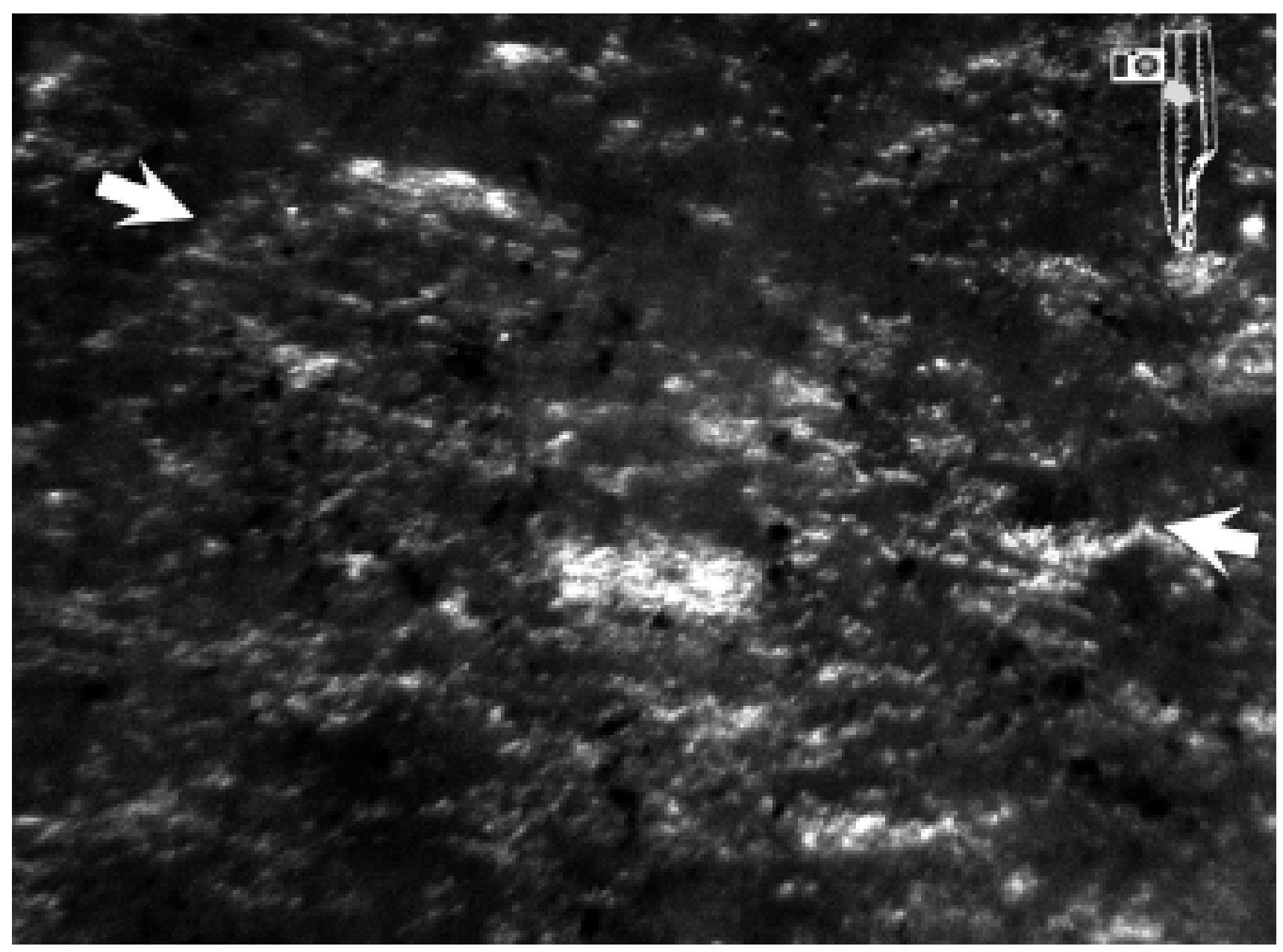

A FiguRA 7. Imagen microscópica, a 100 aumentos, de las marcas de uso como proyectil en una punta solutrense de Chaves. Las flechas enmarcan las huellas funcionales estriadas. 


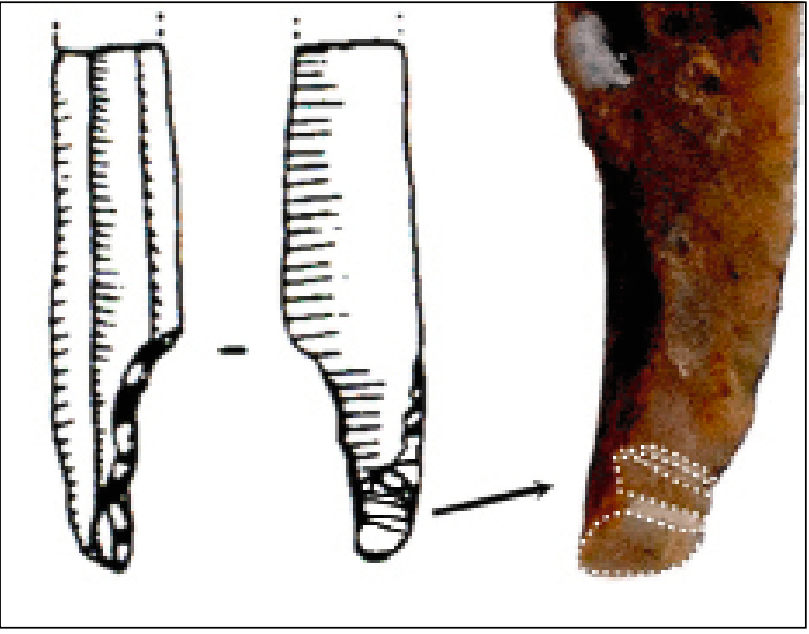

$\Delta$ Figura 8. Imagen de la rotura en charnela del pedúnculo de una punta solutrense de Chaves. Se remarcan mediante líneas discontinuas las ondas de fractura de la charnela.

empleadas, deriva de la limitada frecuencia de aparición de marcas funcionales: dado que esas huellas no se generan por reiteración de uso, sino por impactos o roces rápidos y violentos, las probabilidades de que se produzcan son relativamente reducidas y es habitual registrarlas en porcentajes poco significativos.

Sólo una de las puntas analizadas ha mostrado huellas funcionales microscópicas, una serie de estrías agrupadas en el centro de la cara dorsal de la pieza Ch.C.C1.83, subparalelas al filo, que indicarian su uso como punta de proyectil (Fig. 7).

Tres piezas de Chaves y una de las de Fuente del Trucho muestran fracturas que podemos considerar diagnósticas del empleo como elementos de proyectil: roturas aburiladas o en charnela de los ápices o de los pedúnculos debido al rebote contra el astil. La pieza Ch.C.C1.83 combina huellas microscópicas con una significativa rotura en charnela del pedúnculo (Fig. 8).

En resumen, lo reducido de la muestra y las dificultades de observación detectadas en las colecciones de las cuevas altoaragonesas dificultan el establecimiento de conclusiones generales sobre la utilización de estas piezas. En este sentido, existen pocos datos sobre el empleo de las puntas de muesca solutrenses, careciendo de estudios funcionales específicos. La mayoría de los autores se han centrado en el análisis visual de las fracturas, aspecto en el que destaca $F$. J. Muñoz (2003), quien ha estudiado exhaustivamente las puntas de escotadura del Levante español, especialmente los ejemplares de Parpalló y Ambrosio. Muñoz concluye que se utilizaron para armar flechas, a partir de sus reducidas dimensiones y peso, perfectamente apto para proyectiles ligeros pero insuficiente para mantener el adecuado balance balístico en lanzas o jabalinas. Como es evidente, la mayor parte de elementos recuperados en los sitios son fragmentos proximales, que, una vez rotos durante su empleo, volverian a los lugares de hábitat aún adheridos al astil, para ser sus- tituidos por nuevas puntas. La presencia de roturas diagnósticas en estos sitios alcanza un $26 \%$ en Parpalló y un $37 \%$ en Ambrosio, índices en todo caso inferiores a los detectados por Geneste y Plisson (1990) para piezas morfológicamente similares, pero de retoque plano, de sitios de la Dordoña. Muñoz atribuye esta diferencia a diversos factores de orden metodológico o a condiciones de empleo distintas por lo que se refiere a circunstancias como el tipo de enmangue, la distinta envergadura de las presas cazadas...

\section{CONCLUSIONES}

Las ocupaciones solutrenses del Prepirineo central son por el momento, pese a su reducido número de efectivos, el mejor ejemplo de las relaciones que existen entre el núcleo central del Salpetriense francés y los asentamientos similares que encontramos a lo largo de la costa mediteránea peninsular. Pese a su ubicación en el interior lejos de la ruta costera, Chaves y Fuente del Trucho muestran fuertes conexiones con las ocupaciones del Ródano transmitidas posiblemente por la ruta del Aude - Têt - Segre, bien atestiguada en épocas inmediatamente posteriores (MontIleó - Parco - Cova Gran - Alonsé - Forcas-I), y muy probable ya en estos momentos, según demostrarían las similitudes formales entre las representaciones de prótomos de caballo en las figuras parietales del Trucho y el arte mueble de la Petite Grotte de Bize. Como hemos visto, las puntas de escotadura de Chaves y Fuente del Trucho representan un punto intermedio, morfológicamente hablando, entre las del núcleo Salpetriense y las del Mediterráneo ibérico, si bien su aire general es "más francés", quizás por causa de esa ruta de comunicación propia, que permite contactos más directos a través del Pirineo que por la costa: la zona litoral, notablemente extendida por el descenso del nivel marino, formaría una unidad propia y diferenciada.

Funcionalmente su empleo es claro, aunque la muestra estudiada no ha sido pródiga en la presencia de huellas diagnósticas. Se utilizaron como elementos de proyectil, posiblemente puntas de flechas, a juzgar por su pequeño tamaño, inadecuado para lograr un balance óptimo en lanzas o jabalinas. Las marcas son microscópicas (estrías debidas al roce de fragmentos de sílex desprendidos por el impacto) y macroscópicas (fracturas características, en charnela o aburiladas).

La situación actual de nuestros conocimientos acerca del Paleolítico superior en el valle del Ebro nos hace ser optimistas acerca del futuro de la investigación, pese a las dificultades actuales: hace apenas tres décadas los yacimientos conocidos eran menos de una decena, mientras que ahora rondan el medio centenar, por lo que auguramos para el Solutrense del noreste peninsular un futuro fecundo en hallazgos que ayuden a completar nuestros conocimientos sobre su desarrollo y contexto, por ahora excesivamente esquemático. 


\section{AGRADECIMIENTOS}

Queremos agradecer la magnifica acogida dispensada por el equipo organizador del congreso en Vélez-Blanco, encabezado por el Prof. Ripoll. El impresionante paisaje que rodea a la Cueva de Ambrosio ha quedado grabado en nuestra memoria como recuerdo de una reunión interesante y enriquecedora. Este trabajo se enmarca en la trayectoria del Grupo de Investigación "Primeros pobladores del Valle del Ebro" (H07 del Gobierno de Aragón); la financiación para la asistencia al Congreso y las tareas derivadas ha sido posible gracias al Proyecto "Repensando viejos yacimientos, ampliando nuevos horizontes" (HAR2011 - 27.197), del Ministerio de Economía y Competitividad.

\section{BIBLIOGRAFÍA}

Boccaccio, G. y UtrilLA, P. 2013: "Du Languedoc à I'Aragon: Analyse technologique comparée du Salpêtrien de la Vallée du Rhône et du Solutréen supérieur de la Cueva de Chaves". Le Solutréen... 40 ans après Smith'66, Congrès de Preuilly-sur-Claise, 2007. 47 Supplément a là Revue Archéologique du Centre de la France. Tours.

Calvet, M. 2004: "The Quaternary glaciation of the Pyrenees". En J. Ehlers y P.L. Gibbard (eds.): Quaternary Glaciations - Extent and Chronolog. Elsevier. Amsterdam: 119-218.

Domingo, R. 2005: La funcionalidad de los microlitos geométricos. Bases experimentales para su estudio. Monografías Arqueológicas, 41. Universidad de Zaragoza. Zaragoza.

- 2009: "Caracterización funcional de los microlitos geométricos. El caso del Valle del Ebro". En P. Utrilla y L. Montes (eds.): El mesolitico geométrico en la Península lbérica. Monografías Arqueológicas 44. Universidad de Zaragoza. Zaragoza: 375-389.

- e. p. a: "Analyse fonctionnel des pointes à dos de la Grotte Gazel". En D. Sacchi (ed.): La Grotte Gazel.

- e. p. b: "Análisis funcional de los microlitos geométricos de Forcas Il y de otras piezas de su contexto territorial". En P. Utrilla y C. Mazo (eds.): La Peña de las Forcas (Graus, Huesca). Un asentamiento estratégico en la confluencia del Ésera y el Isábena. Monografías Arqueológicas 46, Universidad de Zaragoza. Zaragoza.

Domingo, R., Utrilla, P. y BeA, M. 2013: "La ocupación gravetiense del Arenal de Fonseca en el rio Guadalope (Ladruñán, Teruel)". Pensando el Gravetiense: nuevos datos para la región Cantábrica en su contexto peninsular. Centro de Investigación y Museo de Altamira: 115-125.

EsCALON DE Fonton, M. 1964: "Un nouveau faciès du Paléolithique supérieur dans la grotte de la Salpêtrière (Remoulins, Gard)". Miscelánea en homenaje al abate Henri Breuil (1877-1961). Diputación Provincial de Barcelona. Instituto de Prehistoria y Arqueología I. Barcelona: 405-421.

FISCHER, A., HANSEN, P. V. y RASMUSSEN, P. 1984: "Macro and micro wear traces on lithic projectile points. Experimental results and prehistoric examples". Journal of Danish Archaeology 3: 19-46.

Garcia Ruiz, J. M. y Marti Bono, C. 2011: "Los depósitos glaciares del valle del Aragón Subordán, Pirineo Centro-occidental español", Cuaternario y Geomorfología 25: 57-81.

GENESTE, J.-M. y PLISSON, H. 1990: "Technologie fonctionnelle des pointes à cran solutréennes: l'apport des nouvelles données de la grotte de Combe-Sauniére (Dordogne)". En J. Kozlowski (ed.): Feuilles de pierre. Les industries à pointes foliacées du Paléolithique supérieur européen. Actes du colloque de Cracovie 1989. Université de Liège. ERAUL, 42: 293-320.

MIR, A. y SALAS, R. 2000: "La cueva de la Fuente del Trucho y su industria lítica arcaizante del Pleniglacial superior (Colungo, Huesca)". Bolskan 17: 9-32.
Montes, L, y Domingo, R. 2013: El asentamiento magdaleniense de Cova Alonsé (Estadilla, Huesca). Monografías Arqueológicas, 48. Universidad de Zaragoza. Zaragoza.

Montes, L., Utrilla, P. y Martinez-BeA, M. 2006: "Trabajos recientes en yacimientos musterienses de Aragón: Una revisión de la transición Paleolítico Medio/Superior en el Valle del Ebro". En J. M. Maillo y E. Baquedano (eds.): Miscelánea en homenaje a Victoria Cabrera. Zona Arqueológica 7 (I): 214-233.

Mangado, X., Tejero, J. M., Fullola, J. M., Petit, M. A., Garcia-Argüelles, P., Garcia, M., Soler, N. y Vaquero, M. 2010: "Nuevos territorios, nuevos grafismos: una visión del paleolítico superior en Catalunya a inicios del siglo XXI". En X. Mangado (coord.): El Paleolítico superior peninsular. Novedades del siglo XXI. SERP. Barcelona: 63-83.

MuÑoz, F. J. 2003: "Les pointes à cran du paléolithique méditerranéen espagnol : technologie et fonctionnalité". Les pointes à cran dans les industries lithiques du paléolithique supérieur récent de l'oscillation de Lascaux à l'oscillation de Bölling. Actes de la table-ronde de Montauban. Préhistoire du sud-ouest, supplément 6: 101-112.

SACCHI, D. 1986: "Le Paléolithique supérieur du Languedoc occidental et du Roussillon". Gallia Préhistoire, XXlème supplément.

UtRILLA, P. 1992: "Aragón/Litoral Mediterráneo. Relaciones durante el Paleolítico". En P. Utrilla (coord.): Aragón/Litoral Mediterráneo: Intercambios culturales durante la Prehistoria. Institución Fernando el Católico. Zaragoza: 9-35.

- 2000: "El Paleolítico en el Valle Medio del Ebro: una "Revista de Prensan en el cambio de milenio". SPAL 9: 81-108.

UtrilLA, P. y MAZo, C. 1994: "El Solutrense en el valle medio del Ebro". En El Solutrense en la península ibérica. Férvedes 1: 89-104.

UtriLla, P. y Montes, L. 2007: "La période 19000-14000BP dans le Bassin de I'Ėbre". En P. Bodu (ed.): Les occupations humaines en Europe Occidentale de 19000 à 14000BP: Approche régionale de la culture matérielle au Badegoulien et au Magdalénien Ancien/ Moyen. Bulletin de la Société Préhistorique Française 104 (4): 797-807.

Utrilla, P., Montes, L., Mazo, C., Alday, A., Rodanés, J. M., Blasco, M. F., Domingo, R. y BeA, M. 2010: "El Paleolítico superior en la cuenca del Ebro a principios del siglo XXI. Revisión y novedades". En X. Mangado (coord.): El Paleolitico superior peninsular. Novedades del siglo XXI. SERP. Barcelona: 23-61.

Utrilla, P., Baldellou, V., BeA, M. y ViÑAS, R. 2013: "La cueva de la Fuente del Trucho (Asque- Colungo, Huesca). Una cueva mayor del arte gravetiense". Pensando el Gravetiense: nuevos datos para la Región Cantábrica en su contexto. Centro de Investigación y Museo de Altamira.

VilLAVERDE, V. y Fullola, J. M. 1990: "Le solutréen de la zone méditerranéenne espagnole". Feuilles de pierre. Les industries à pointes foliacées du Paléolithique supérieur européen. En J. Kozlowski (éd): Actes du colloque de Cracovie 1989. Université de Liège. ERAUL 42: 467-480. 